\section{Schwangerschaftsdauer und Frühgeburtlichkeit: Welche Rolle spielen die Gene?}

Zhang $\mathrm{G}$ et al. Genetic associations with gestational duration and spontaneous preterm birth. N Engl J Med 2017; 377: 1156-1167. doi:10.1056/NEJMoa1612665

Dass die mütterliche und kindliche Genausstattung den Geburtstermin beeinflussen, wird schon länger vermutet. Nun ist es US-Forschern gelungen, verschiedene maternale Genvarianten zu identifizieren, die nachweislich mit der Schwangerschaftsdauer und dem Frühgeburtsrisiko assoziiert sind.

Die Dauer einer Schwangerschaft sowie das Risiko für eine spontane Frühgeburt sind von genetischen Faktoren abhängig, das belegen die Ergebnisse einer im New England Journal veröffentlichten Arbeit. Die Wissenschaftler haben im Rahmen einer genomweiten Assoziationsstudie 43568 Frauen (mehrheitlich europäischer Abstammung) genotypisiert. Von allen Probandinnen lagen Informationen zur Dauer der ersten ausgetragenen Einlingsschwangerschaft vor. Frauen mit einer Frühgeburt aufgrund einer medizinischen Indikation wurden von der Analyse ausgeschlossen.

Anschließend wurden die Ergebnisse anhand der Daten von weiteren 8643 Müttern und 4090 Kindern überprüft. Dieses Bestätigungskollektiv umfasste eine große Anzahl von Frühgeburten. Ferner wurde überprüft, ob die gefundenen Single-Nukleotid-Polymorphismen (SNPs) zuvor bereits in einem anderen Zusammenhang funktionell charakterisiert worden waren.

Im Primärkollektiv hatten $86,8 \%$ der Frauen in Terminnähe (37-42 SSW) entbunden, $7,6 \%$ vor $37 \mathrm{SSW}$ und $5,6 \%$ nach 42 SSW. Das mütterliche Alter erwies sich als signifikanter Einflussfaktor bezüglich der Schwangerschaftsdauer. In beiden maternalen Testkollektiven konnte für 6 verschiedene Genloci ein signifikanter Zu-

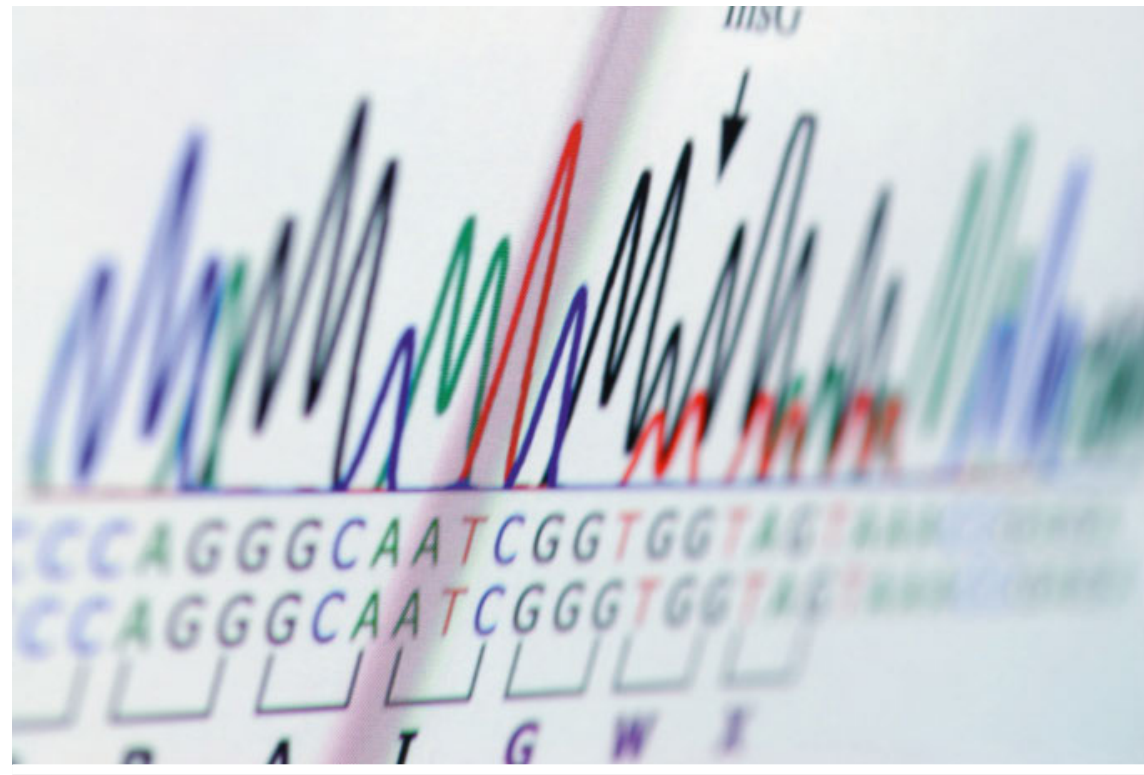

Die Dauer einer Schwangerschaft wird durch mütterliche Genvarianten beeinflusst. Quelle: lily/Fotolia.com

sammenhang mit dem Gestationsalter nachgewiesen werden: EBF1, EEFSEC, AGTR2, WNT4, ADCY5 sowie RAP2C. Für EBF1, EEFSEC sowie AGTR2 bestand zudem ein signifikanter Zusammenhang mit dem Frühgeburtsrisiko. Im Bestätigungskollektiv der Kinder zeigten sich dieselben Assoziationen wie in den maternalen Kollektiven, allerdings fielen die Effektstärken geringer aus. Die Analyseergebnisse der Mutter-Kind-Paare deuteten darauf hin, dass der Einfluss der genetischen Varianten auf die Schwangerschaftsdauer und das Frühgeburtsrisiko nicht auf den fetalen, sondern auf den maternalen Genotyp zurückzuführen ist.

Für SNPs des EEFSEC-Locus war zuvor bereits eine Assoziation mit einem erhöhten Prostatakarzinomrisiko, einem geringeren Hypospadierisiko sowie einem späteren Menarchealter nachgewiesen worden. SNPs des WNT4-Locus waren mit dem Risiko für eine Endometriose, für ein Ovarialkarzinom sowie mit der Knochendichte assoziiert. Ein Zusammenhang mit dem Geburtsgewicht bestand für SNPs der Loci ADCY5, WNT4 und EBF1.
Funktionelle Analysen des WNT4-Locus deuteten darauf hin, dass die Dezidualisierung des Endometriums bezüglich des Frühgeburtsrisikos eine wesentliche Rolle spielt: Varianten von WNT4 scheinen die Bindung des Östrogenrezeptors zu beeinflussen.

\section{FAZIT}

Sechs maternale Genloci, so das Fazit der Autoren, haben nachweislich einen Einfluss auf den Geburtstermin. In 3 Fällen bestehe zusätzlich ein Zusammenhang mit dem Frühgeburtsrisiko. Auf funktionell-mechanistischer Ebene sei die Assoziation der Gene mit der Schwangerschaftsdauer nachvollziehbar: Ein Zusammenhang mit der Uterusentwicklung, der maternalen Nährstoffsituation, der uteroplazentaren Vaskularisierung sowie der hormonellen Signalwege sei zu vermuten.

\section{Dr. med. Judith Lorenz, Künzell}

